\title{
Proinflammatory cytokines and IL-10 in inflammatory bowel disease and colorectal cancer patients
}

\section{Andrzej Szkaradkiewicz¹, Ryszard Marciniak², Izabela Chudzicka-Strugała ${ }^{1}$, Agnieszka Wasilewska ${ }^{2}$, Michał Drews ${ }^{2}$, Przemysław Majewski ${ }^{3}$, Tomasz Karpiński ${ }^{1}$ and Barbara Zwoździak ${ }^{1}$}

\author{
${ }^{1}$ Department of Medical Microbiology, University of Medical Sciences, Poznań, Poland, \\ ${ }^{2}$ Department of General, Gastroenterological, and Endocrinological Surgery, University of Medical Sciences, Poznań, \\ Poland \\ ${ }^{3}$ Department of Clinical Pathomorphology, University of Medical Sciences, Poznań, Poland
}

Received: 2008.08.18, Accepted: 2009.01.10, Published online: 2009.07.04

(C) L. Hirszfeld Institute of Immunology and Experimental Therapy, Wrocław, Poland 2009

\begin{abstract}
Introduction: The aim of the study was to describe the levels of circulating monocyte/macrophage pro-inflammatory cytokines (TNF- $\alpha$, IL-1 $\beta$, IL-6, and IL-8) and an anti-inflammatory cytokine (IL-10) in inflammatory bowel disease (IBD) and colorectal cancer (CRC) patients and healthy controls.

Materials and Methods: The study was conducted on 15 healthy individuals, 20 patients with ulcerative colitis (UC), 12 with Crohn's disease (CD), and 15 with CRC (Dukes' stage B). Blood serum cytokine levels were measured by ELISA.

Results: The patients with UC had significantly higher levels of the pro-inflammatory cytokines and of circulating IL-10 than the healthy controls. The patients with $\mathrm{CD}$ and CRC had the same specific pattern of serum cytokines of significantly elevated levels of the pro-inflammatory cytokines, but the IL-10 levels were within the range found in the healthy individuals. Conclusions: Thus our results demonstrate that both IBD and CRC are linked with an intensified production of a wide array of monocyte/macrophage pro-inflammatory cytokines which is not accompanied by elevated levels of circulating IL-10, except for its insufficiently inhibitory elevation in UC patients.
\end{abstract}

Key words: cytokines, inflammation, Crohn's disease, ulcerative colitis, colorectal cancer.

Corresponding author: Prof. Andrzej Szkaradkiewicz, Department of Medical Microbiology, University of Medical Sciences, Wieniawskiego 3, 61-712 Poznań, Poland, tel./fax: +48 61-8546140, e-mail: szkaradkiewicza@poczta.onet.pl

\section{INTRODUCTION}

Crohn's disease (CD) and ulcerative colitis (UC) are inflammatory bowel diseases (IBDs) characterized by chronic relapsing inflammation of the gut that ultimately leads to destruction of the intestinal tissue. Although their etiology is not yet fully known, the initiation and aggravation of the inflammatory process seem to be due to a dysregulated immune responses with a parallel increase in the expressions of pro-inflammatory cytokines, including tumor necrosis factor (TNF)- $\alpha$, interleukin (IL)-1 $\beta$, IL-6, and IL-8 (Hyun and Mayer 2006; Shih and Targan 2008). At the same time, deficiency of IL-10, an anti-inflammatory cytokine, seems to contribute to persistent intestinal inflammation ( $\mathrm{Li}$ and He 2004; Shih and Targan 2008). Clinical reports have well document an increased risk of intestinal cancer in
UC and CD patients (Askling et al. 2001; Eaden et al. 2001; Jess et al. 2005). However, it is still unclear if any relationship exists between pro-inflammatory cytokine and IL-10 expression in IBD and the development of intestinal neoplasms.

Considering the above, the aim of the present study was to describe the levels of circulating pro-inflammatory cytokines (TNF- $\alpha$, IL-1 $\beta$, IL-6, and IL-8) and IL-10 in IBD and colorectal cancer (CRC) patients.

\section{MATERIALS AND METHODS}

\section{Patients}

The study was conducted on 47 patients hospitalized at the Department of General, Gastroenterological, 
and Endocrinological Surgery, University of Medical Sciences in Poznań, Poland, and 15 healthy subjects representing the control group. Employing standard clinical, radiological, endoscopic, and histopathological criteria (except for histopathological diagnosis in the healthy subjects), four study groups were distinguished. Group 1 included the 15 control healthy volunteers (6 men and 9 women, age range: $25-63$, mean: 42.5 years) who manifested no organic disease, including normal endoscopy. No patients with post-infectious colitis were included. Group 2 included 20 patients (10 men and 10 women, age range: $21-50$, mean: 39.5 years) with active UC with an average duration of 5.9 years (range: $0.5-25$ years) and activity estimated using the histological scoring system according to Geboes et al. (Geboes et al. 2000) amounting to 4.3 in 14 patients and 5.3 in the remaining 6 patients. Group 3 included 12 patients $(6$ men and 6 women, age range: $15-42$, mean: 28.6 years) with active $\mathrm{CD}$ with an average duration of 4.2 years (range: 0.5-34 years) and an average clinical activity CDAI score of over 150 points (Best et al. 1976). Group 4 included 15 patients (5 men and 10 women, age range: 40-69 years, mean: 60.7 years) with an average duration of symptoms of 0.66 years (range: $0.5-0.8$ year). In the CD patients, stage B (Dukes' classification) of CRC was diagnosed, with no infiltration of regional organs and no metastasis. The patient groups showed no signs of infection. The standard surgical treatment was applied in all the patients. The IBD patients were receiving steroids (prednisone and sulfasalazin). However, in the preoperative period the drug doses were reduced to discontinue them within 7-10 days before the planned operative procedure.

Venous blood was sampled from the patients 24 $\mathrm{h}$ before surgical treatment. It was the centrifuged at $1500 \times \mathrm{g}$ for $15 \mathrm{~min}$ at room temperature and, the serum was collected and frozen $\left(-80^{\circ} \mathrm{C}\right)$. The cytokine levels were determined after collection of all the sera. All the research protocols were reviewed and approved by the ethics committee of the university.

\section{Measurement of cytokines}

The levels of TNF- $\alpha$, IL-1 $\beta$, IL-6, IL-8, and IL-10 were established in the sera of all the participants by ELISA, using the Quantikine kit for the detection of IL-8 and Quantikine HS (both R\&D Systems, Abingdon, UK) for the detection of the remaining cytokines. The minimum levels detectable using the ELISA kits were $0.106 \mathrm{pg} / \mathrm{ml}$ for TNF- $\alpha, 0.057 \mathrm{pg} / \mathrm{ml}$ for IL-1 $\beta, 0.039 \mathrm{pg} / \mathrm{ml}$ for IL-6, $3.5 \mathrm{pg} / \mathrm{ml}$ for IL-8, and 0.5 $\mathrm{pg} / \mathrm{ml}$ for IL-10. The tests were conducted according to the manufacturer's instructions. The optical density was read using a microplate reader (bioMerieux Reader 250) at $\lambda=450 \mathrm{~nm}$ in the IL- 8 assay and $\lambda=490 \mathrm{~nm}$ for the remaining cytokines. The cytokine content of each serum was tested three times and the results expressed in $\mathrm{pg} / \mathrm{ml}$ are the means of these.

\section{Statistical analysis}

The results were expressed as the mean \pm standard deviation (SD). The Mann-Whitney test was used to evaluate the significance of differences between the groups at a $p<0.05$ level of significance.

\section{RESULTS}

The levels of TNF- $\alpha$, IL-1 $\beta$, IL-6, IL-8, and IL-10 detected in the sera of the healthy individuals (group 1) represented the normal values with which the levels obtained in the patient groups were compared. The levels are presented in Table 1 and Fig. 1.

The UC patients had significantly higher levels of TNF- $\alpha$, IL-1 $\beta$, IL-6, IL-8, and IL-10 than the control group.

The CD patients also had significantly higher levels of TNF- $\alpha$, IL-1 $\beta$, IL- 6 , and IL- 8 than the control group, but the level of IL-10 was not significantly different from the normal value. The UC patients had significantly lower levels of TNF- $\alpha$ and IL-8 and significantly higher levels of IL-10 than the CD patients (Table 2).

The CRC patients had significantly higher levels of TNF- $\alpha$, IL-1 $\beta$, IL-6, and IL- 8 than the control group, but the level of IL-10 was not significantly different from the normal value. The CRC patients had significantly higher levels of TNF- $\alpha$ and IL-8 and a significantly lower level of IL-10 than the UC patients. The cytokine levels in the CRC and CD patients showed no significant differences (Table 2).

\section{DISCUSSION}

This study analyzed the levels of the circulating pro-inflammatory cytokines TNF- $\alpha$, IL- $1 \beta$, IL- 6 , and IL-8 and the anti-inflammatory cytokine IL-10 in patients with IBD and patients with CRC. The first set of cytokines promotes inflammatory host reactions in response to various damaging agents, including microbial products (Oppenheim and Neta 1994). Antigen-presenting cells, mainly monocytes/macrophages, are their principal source and therefore manifest a broad immunostimulatory activity (Medzhitov and Janeway 1997). IL-10, produced mainly by T helper lymphocytes (Th) and regulatory $\mathrm{T}$ cells $\left(\mathrm{T}_{\mathrm{Reg}}\right)$, exerts a strong suppressive role on the production of pro-inflammatory cytokines and a regulatory role on Th immune reactions (Mosmann and Sad 1996; Pestka et al. 2004; Taylor et al. 2006).

In this study, elevated levels of the monocyte/macrophage pro-inflammatory cytokines were detected in the sera of patients with either UC or CD. The results point to a continuous activation of monocytes/macrophages in the course of IBD and correspond to other results (Hyun and Mayer 2006; Rogler and Andus 1998). Nevertheless, the causal factors beyond 
Table 1. Cytokine levels (TNF- $\alpha$, IL-1 $\beta$, IL-6, IL-8, IL-10) in sera of the healthy subjects and patients with UC, CD, or CRC

\begin{tabular}{|c|c|c|c|c|c|}
\hline \multirow[t]{2}{*}{ Studied groups } & \multicolumn{5}{|c|}{ Means values in $\mathrm{pg} / \mathrm{ml} \pm \mathrm{SD}$ and range in parentheses [median values] } \\
\hline & TNF- $\alpha$ & IL-1 $\beta$ & IL-6 & IL-8 & IL-10 \\
\hline $\begin{array}{l}\text { Healthy subjects } \\
\text { (group } 1, \mathrm{n}=15 \text { ) }\end{array}$ & $\begin{array}{c}0.61 \pm 0.28 \\
(0.10-1.0) \\
{[06]}\end{array}$ & $\begin{array}{c}0.12 \pm 0.10 \\
(0.0-0.2) \\
{[0.16]}\end{array}$ & $\begin{array}{c}1.59 \pm 0.90 \\
(0.6-3.2) \\
{[1.18]}\end{array}$ & $\begin{array}{c}9.77 \pm 7.65 \\
(0.0-22.1) \\
{[9.9]}\end{array}$ & $\begin{array}{c}1.35 \pm 0.96 \\
(0.0-2.8) \\
{[1.65]}\end{array}$ \\
\hline $\begin{array}{l}\text { Patients with UC } \\
\text { (group } 2, \mathrm{n}=20 \text { ) }\end{array}$ & $\begin{array}{c}1.18 \pm 0.73^{*} \\
(0.1-2.5) \\
{[1.1]}\end{array}$ & $\begin{array}{c}1.35 \pm 1.21^{*} \\
(0.4-4.6) \\
{[0.86]}\end{array}$ & $\begin{array}{c}8.63 \pm 2.14^{*} \\
(4.8-12.8) \\
{[8.6]}\end{array}$ & $\begin{array}{c}31.84 \pm 12.97^{*} \\
(14.6-61.3) \\
{[28.0]}\end{array}$ & $\begin{array}{c}4.40 \pm 1.55^{*} \\
(2.0-6.7) \\
{[4.28]}\end{array}$ \\
\hline $\begin{array}{l}\text { Patients with CD } \\
\text { (group } 3, n=12 \text { ) }\end{array}$ & $\begin{array}{c}3.12 \pm 2.42^{*} \\
(1.5-7.8) \\
{[1.875]}\end{array}$ & $\begin{array}{c}0.94 \pm 0.84^{*} \\
(0.3-2.8) \\
{[0.415]}\end{array}$ & $\begin{array}{c}8.24 \pm 1.75^{*} \\
(5.8-10.8) \\
{[8.7]}\end{array}$ & $\begin{array}{c}53.70 \pm 41.52^{*} \\
(28.0-149.8) \\
{[37.6]}\end{array}$ & $\begin{array}{c}2.16 \pm 1.46 \\
(0.0-3.9) \\
{[2.5]}\end{array}$ \\
\hline $\begin{array}{l}\text { Patients with CRC } \\
\text { (group } 4, n=15 \text { ) }\end{array}$ & $\begin{array}{c}1.9 \pm 1.00^{*} \\
(0.9-3.8) \\
{[1.51]}\end{array}$ & $\begin{array}{c}1.44 \pm 0.98^{*} \\
(0.4-3.2) \\
{[1.16]}\end{array}$ & $\begin{array}{c}10.51 \pm 3.33^{*} \\
(7.5-18.0) \\
{[9.9]}\end{array}$ & $\begin{array}{c}49.74 \pm 31.67^{*} \\
(29.0-168.0) \\
{[38.0]}\end{array}$ & $\begin{array}{c}1.99 \pm 1.19 \\
(0.24-4.2) \\
{[2.0]}\end{array}$ \\
\hline
\end{tabular}

"Significant difference in cytokine level between the patients and healthy subjects.

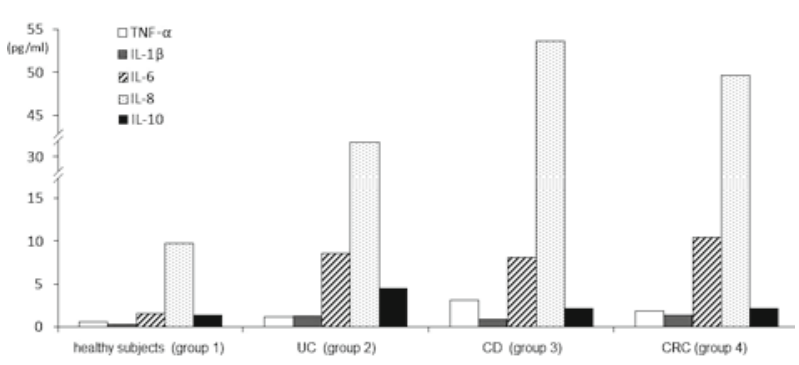

Fig. 1. Serum cytokine levels in studied groups of patients.

the activation of the cells are incompletely understood, although experiments on animal models provide evidence for the importance of antigens of commensal bacteria in stimulation of the mucosal immune system (Rennick and Fort 2000; Sartor 2004). Mycobacterium avium subspecies paratuberculosis is also currently suggested to determine bacterial signals which induce the pro-inflammatory response in CD (Bull et al. 2003; Szkaradkiewicz et al. 2007). Monocyte/macrophage activation is also augmented by the Th1 response, expressed by the elevated secretion of interferon- $\gamma$ and IL-12 in patients with CD (Autschbach et al. 2002; Plevy et al. 1997).

The involvement of Th17 lymphocytes, which produce IL-6/IL-17, has been demonstrated in the development the inflammatory process in CD (Fujino et al.

Table 2. Statistical comparison of cytokine levels in patients with UC, CD, and CRC

\begin{tabular}{lccccc}
\hline \multirow{2}{*}{$\begin{array}{c}\text { Examined } \\
\text { groups }\end{array}$} & \multicolumn{5}{c}{$\mathrm{p}$ (Mann-Whitney test) } \\
\cline { 2 - 6 } & TNF- $\alpha$ & IL-1 $\beta$ & IL-6 & IL-8 & IL-10 \\
\hline UC vs. CD & $<0.05$ & 0.1571 & 0.9222 & $<0.05$ & $<0.05$ \\
UC vs. CRC & $<0.05$ & 0.5157 & 0.0770 & $<0.05$ & $<0.05$ \\
CD vs. CRC & 0.1020 & 0.0645 & 0.0639 & 0.7407 & 0.6255 \\
\hline
\end{tabular}

2003; Yen et al. 2006). On the other hand, in UC the inflammatory response seems to be dominated by Th2 lymphocytes, which secrete high amounts of IL-5 and IL-13 (Fuss et al. 2004). The increase in circulating IL-10 level in UC demonstrated in this study, in turn, seems to result from the activity of $\mathrm{T}_{\text {Reg }}$ cells. This conclusion can be backed up by results documenting the expression of transforming growth factor- $\beta 1$, which is also released by $\mathrm{T}_{\mathrm{Reg}}$ cells, in patients with UC (Taylor et al. 2006; Wiercińska-Drapało et al. 2001). Thus it seems possible that the induced $\mathrm{T}_{\mathrm{Reg}}$ cells suppressing an immune response cause the inflammation in UC to be more superficial than the transmural pathological process in CD. Nevertheless, in the presented results, except for TNF- $\alpha$ and IL-8, no significant differences were detected between the elevated concentrations of the pro-inflammatory cytokines in the sera of the patients with UC or CD. These data may indicate that the relatively low production of IL-10 in UC is insufficient to inhibit the secretory activity of monocytes/macrophages. Thus, the currently well-established $\mathrm{T}_{\mathrm{Reg}}$-Th cell interactions (Groux et al. 1997; Taylor et al. 2006) may be of decisive significance for the course of IBD.

In the sera of the patients with $\mathrm{CRC}$, a significant elevation was also noted in the levels of the pro-inflammatory cytokines TNF- $\alpha$, IL-6, and IL-8, consistent with the results earlier presented by other authors (Belluco et al. 2000; Kamińska et al. 2000). Moreover, the levels of the cytokines in the patients with CRC and those with CD showed no significant differences. In parallel, the levels of circulating IL-10 in CRC and CD were within the normal range. These data, presented for the first time in this study, document the same specific pattern of the serum cytokine levels in patients with CRC or CD characterized by the stimulated production of monocyte/macrophage pro-inflammatory cytokines in the presence of normal circulating levels of IL-10. Already published data have presented contradictory results 
related to preoperative serum IL-10 levels in CRC patients, pointing to a relationship between higher IL-10 levels and an inoperable tumor (Galizia et al. 2002; Kamińska et al. 2000). On the other hand, our study was conducted in patients with operable CRC (Dukes' stage B), which may explain the contradictions.

Thus our results demonstrate that both IBD and operable CRC are accompanied by augmented production of a wide array of monocyte/macrophage pro-inflammatory cytokines. The level of circulating IL-10, in turn, remained within the range of normal values, except for its elevated level in UC which, nevertheless, was not sufficient to inhibit the secretory activity of monocytes/macrophages. Disturbed equilibrium between pro- and anti-inflammatory cytokine responses seems to play a significant role in the pathogeneses of IBD and CRC.

Acknowledgment: This study was supported by a grant from the University of Medical Sciences in Poznań, Poland.

\section{REFERENCES}

Askling J, Dickman PW, Karlen P et al (2001) Colorectal cancer rates among first-degree relatives of patients with inflammatory bowel disease: a population-based cohort study. Lancet 357:262-266

Autschbach F, Giese T, Gassler N et al (2002) Cytokine/chemokine messenger-RNA expression profiles in ulcerative colitis and Crohn's disease. Virchows Arch 441:500-513

Belluco C, Nitti D, Frantz M et al (2000) Interleukin-6 blood levels is associated with circulating carcinoembryonic antigen and prognosis in patients with colorectal cancer. Ann Surg Oncol 7:133-138

Best WR, Becktel JM, Singleton JW et al (1976) Development of a Crohn's disease activity index. Gastroenterology 70:439-444

Bull TJ, McMinn EJ, Sidi-Boumedine K et al (2003) Detection and verification of Mycobacterium avium subsp. paratuberculosis in fresh ileocolonic mucosal biopsy specimens from individuals with and without Crohn's disease. J Clin Microbiol 41:2915-2923

Eaden JA, Abrams KR, Mayberry JF (2001) The risk of colorectal cancer in ulcerative colitis: a meta-analysis. Gut 48:526-535

Fujino S, Andoh A, Bamba S et al (2003) Increased expression of interleukin 17 in inflammatory bowel disease. Gut 52:65-70

Fuss IJ, Heller F, Boirivant M et al (2004) Nonclassical CD1d-restricted NK T cells that produce IL-13 characterize an atypical Th2 response in ulcerative colitis. J Clin Invest 113:1490-1497

Galizia G, Orditura M, Romano C et al (2002) Prognostic significance of circulating IL-10 and IL-6 serum levels in colon cancer patients undergoing surgery. Clin Immunol 102: 169-178
Geboes K, Riddell R, Öst A et al (2000) A reproducible grading scale for histological assessment of inflammation in ulcerative colitis. Gut 47:404-409

Groux H, O’Garra A, Bigler M et al (1997) A CD4+ T-cell subset inhibits antigen-specific T-cell responses and prevents colitis. Nature 389:737-742

Hyun JG, Mayer L (2006) Mechanisms underlying inflammatory bowel disease. Drug Discov Today Dis Mech 3:457-462

Jess T, Gamborg M, Matzen P et al (2005) Increased risk of intestinal cancer in Crohn's disease: a meta-analysis of population-based cohort studies. Am J Gastroenterol 100:2724-2729

Kamińska J, Kowalska MM, Nowacki MP et al (2000) CRP, TNF-a, IL-1ra, IL-6, IL-8 and IL-10 in blood serum of colorectal cancer patients. Pathol Oncol Res 6:38-41

Li MC, He SH (2004) IL-10 and its related cytokines for treatment of inflammatory bowel disease. World J Gastroenterol 10:620-625

Medzhitov R, Janeway CA (1997) Innate immunity: impact on the adaptive immune response. Curr Opin Immunol 9:4-9

Mosmann TR, Sad S (1996) The expanding universe of T-cell subsets: Th1, Th2 and more. Immunol Today 17:138-146

Oppenheim JJ, Neta R (1994) Pathophysiological roles of cytokines in development, immunity and inflammation. FASEB J 8:158-162

Pestka S, Krause CD, Sarkar D et al (2004) Interleukin-10 and related cytokines and receptors. Annu Rev Immunol 22:929-979

Plevy SE, Landers CJ, Prehn J (1997) A role for TNF-alpha and mucosal $\mathrm{T}$ helper-1 cytokines in the pathogenesis of Crohn's disease. J Immunol 159:6276-6282

Rennick DM, Fort MM (2000) Lessons from genetically engineered animal models. XII. IL-10-deficient (IL-10-/-) mice and intestinal inflammation. Am J Physiol Gastrointest Liver Physiol 278:G829-833

Rogler G, Andus T (1998) Cytokines in inflammatory bowel disease. World J Surg 22:382-389

Sartor RB (2004) Therapeutic manipulation of the enteric microflora in inflammatory bowel disease: antibiotics, probiotics, and prebiotics. Gastroenterology 126:1620-1633

Shih DQ, Targan SR (2008) Immunopathogenesis of inflammatory bowel disease. World J Gastroenterol 14:390-400

Szkaradkiewicz A, Chudzicka-Strugala I, Zwozdziak B (2007) Mycobacterium avium subsp. paratuberculosis in inflammatory bowel diseases. Przegl Epidemiol 61:85-90

Taylor A, Verhagen J, Blaser K et al (2006) Mechanisms of immune suppression by interleukin-10 and transforming growth factor- $\beta$ : the role of T regulatory cells. Immunology 117:433-442

Wiercińska-Drapało A, Flisiak R, Prokopowicz D (2001) Effect of ulcerative colitis activity on plasma concentration of transforming growth factor beta1. Cytokine 14:343-346

Yen D, Cheung J, Scheerens H et al (2006) IL-23 is essential for $\mathrm{T}$ cell-mediated colitis and promotes inflammation via IL-17 and IL-6. J Clin Invest 116:1310-1316 